\title{
GENDER EFFECT ON PERCEIVED NEED SUPPORT FROM THE TEACHER AND PEERS IN PHYSICAL EDUCATION
}

\author{
R. Viira, A. Koka
}

Faculty of Exercise and Sport Sciences, University of Tartu, Estonia

\begin{abstract}
The purpose of the present study was to examine gender differences in perceptions of basic psychological needs support from the teacher and peers in physical education. The 659 Estonian secondary school students ( 310 boys and 349 girls; $M$ age $=13.57$ years, $S D=0.62$ ) completed questionnaires assessing the perceptions of autonomy, competence, and relatedness need support from both the teacher and peers in physical education. Results of the independent samples t-tests revealed that boys scored significantly higher than girls on perceptions of all three need support from the teacher, whereas girls scored significantly higher than boys on perceptions of all three need support from peers. Results are discussed in relation with practical implications to physical education teachers in order to facilitate the satisfaction of the basic psychological needs for both boys and girls more efficiently.
\end{abstract}

Key words: adolescents; psychological needs for autonomy, competence, and relatedness; self-determination theory, significant others

\section{INTRODUCTION}

According to self-determination theory (SDT), introduced by Deci and Ryan [4], overall healthy functioning as well as self-determined learning in school is dependent on the satisfaction of three basic 
psychological needs for autonomy, competence, and relatedness. There are few studies in physical education (PE) that have examined the effect of basic psychological need-supporting context on students' needs satisfaction and motivation $[10,12]$. Standage and colleagues [12], for example, showed that multifaceted need-supporting behaviour from the teacher encompassing perception of autonomy, competence, and relatedness support positively predicted students' self-determined motivation in PE mediated by perceived need satisfaction.

There is evidence in literature dealing with gender differences in PE that teachers tend to interact with students differently. Davis's [3] review of literature suggests that PE teachers interact verbally more often with boys than girls. For example, past research has shown that boys perceived their PE teachers asking them questions [2,6] and providing them with positive general feedback (i.e., praise and encouragement) more often compared to girls [9]. Moreover, studies have documented that there is not always congruence between what a teacher actually says and how students perceive and interpret the information [7]. Therefore, it is necessary to investigate how students perceive and interpret various aspects of student-teacher interaction in PE. It is not clear so far, however, is there any gender differences in perceptions of the three basic psychological needs support from the PE teacher.

According to Sage and Kindermann [11], the interaction between peers in classroom may have proportionally even greater influence on children's different psychological aspects of participation in PE than those of teachers because teachers' influence is considered to be more distal. Bearing this in mind, one may argue that perception of autonomy, competence, and relatedness support from the teacher is not the sole source of basic psychological needs support for students in PE. Interestingly, however, there is no evidence regarding the effect of gender on the perceptions of autonomy, competence, and relatedness needs support from peers in PE.

The aim of the present study was to investigate gender differences in perceived psychological needs support from both the teacher and peers in PE. According to previous research [2, 6, 9], it was hypothesized that boys exhibit higher perceptions of autonomy, competence, and relatedness needs support from the PE teacher than girls. Regarding the hypothesis on the existence of gender differences in perceptions of autonomy, competence, and relatedness needs 
support from peers in PE, no a priori hypothesis was proposed because of any previous findings in this specific domain.

\section{METHODS}

\section{Subjects}

The participants were 659 (310 boys and 349 girls; M age=13.57 years, $\mathrm{SD}=0.62$ ) secondary school students from a town located in southeast of Estonia. Prior to data collection, permission to carry out the study was obtained from the head teachers of all schools. The informed consent was obtained from the participants and their parents via a letter sent home with each child. Parents' permission was considered approved if they did not send the letter back to the school. No letters were returned. Students were administered with the questionnaires that took approximately $10 \mathrm{~min}$ to complete in their 'home room' during the regular school day. Students were assured about the confidentiality of their answers.

\section{Measures}

Perceived Psychological Need Support from the Teacher in PE. To assess the degree to which the students perceived the PE teacher to support their needs for autonomy, competence, and relatedness in PE, 15-item need support scale devised by Standage and colleagues [12] was used. All items were preceded by the same stem, "In this PE class...", and students responded on 7-point scale ranging from 1 (strongly disagree) to 7 (strongly agree). An example items from the scale are as follows: "...I feel that the teacher provides me with choices and options" (autonomy support; 6 items), "...the teacher makes me feel like I am good at PE" (competence support; 4 items), and "...the teacher encourages me to work with others in class activities" (relatedness support; 5 items). In the present study, the Cronbach's alphas for autonomy support, competence support, and relatedness support subscales were $0.86,0.67$, and 0.87 , respectively. Furthermore, CFA supported the proposed three-factor structure of the scale. The goodness of fit test parameters were: $\chi^{2}(87)=263.75$, $p=0.001, \chi^{2} / \mathrm{df}$ ratio $=3.03, \mathrm{CFI}=0.94, \mathrm{NNFI}=0.92, \mathrm{RMSEA}=0.057$, $90 \%$ confidence interval $\left(\mathrm{CI}_{90}\right)$ for RMSEA range $=0.049$ to 0.065 . 
Perceived Psychological Need Support from Peers in PE. To assess the degree to which students perceived peers to support their needs for autonomy, competence, and relatedness need in PE, items derived from the 15-item need support scale was used that was originally designed to assess perceptions of the need support from the teacher in PE [12]. The original items were modified by changing the 'teacher' to 'peers' as the salient referent. All items again were preceded by the same stem, "In this PE class...", and students responded on 7-point scale ranging from 1 (strongly disagree) to 7 (strongly agree). An example items from the scale are as follows: “...I feel that the peers provide me with choices and options" (autonomy support; 6 items), “...the peers make me feel like I am good at PE" (competence support; 4 items), and "...the peers encourage me to work with others in class activities" (relatedness support; 5 items). In the present study, the Cronbach's alphas for autonomy support, competence support, and relatedness support subscales were $.87, .84$, and .88 , respectively. Results of the CFA yielded acceptable fit indices: $\quad \chi^{2}(87)=244.91, \quad p=0.001, \quad \chi^{2} / \mathrm{df} \quad$ ratio $=2.82, \quad \mathrm{CFI}=0.95$, $\mathrm{NNFI}=0.93, \mathrm{RMSEA}=0.054, \mathrm{CI}_{90}$ for $\mathrm{RMSEA}$ range $=0.046$ to 0.062 .

\section{Data Analysis}

Independent-samples T-tests were used to investigate gender differences on perceptions of autonomy, competence, and relatedness needs support from both the PE teacher and peers.

\section{RESULTS}

Independent-samples T-tests revealed that there were significant gender differences on all study variables (see Figure 1). Results indicated that while boys scored significantly higher on perceptions of autonomy, competence, and relatedness needs support from the PE teacher, the girls scored significantly higher on perceptions of autonomy, competence, and relatedness needs support from peers. Specifically, boys perceived significantly more that their PE teacher provided them with autonomy support $\left(\mathrm{M}_{\text {boys }}=4.28 \pm 1.32\right.$ vs $\mathrm{M}_{\text {girls }}=3.98 \pm 1.23$, $\mathrm{p}<0.01)$, competence support $\left(\mathrm{M}_{\text {boys }}=5.27 \pm 1.34\right.$ vs $\mathrm{M}_{\text {girls }}=4.99 \pm 1.24$, $\mathrm{p}<0.01)$, and relatedness support $\left(\mathrm{M}_{\text {boys }}=4.62 \pm 1.38\right.$ vs $\mathrm{M}_{\text {girls }}=4.38 \pm 1.39, \mathrm{p}<0.05$ ), whereas girls perceived significantly more 
that their peers provided them with autonomy support $\left(\mathrm{M}_{\text {girls }}=4.76 \pm 1.27\right.$ vs $\left.\mathrm{M}_{\text {boys }}=4.18 \pm 1.37, \mathrm{p}<0.001\right)$, competence support $\left(\mathrm{M}_{\text {girls }}=4.77 \pm 1.35\right.$ vs $\left.\mathrm{M}_{\text {boys }}=4.30 \pm 1.50, \mathrm{p}<0.001\right)$, and relatedness support $\left(\mathrm{M}_{\text {girls }}=5.33 \pm 1.28 \mathrm{vs} \mathrm{M}_{\text {boys }}=4.53 \pm 1.39, \mathrm{p}<0.001\right)$.

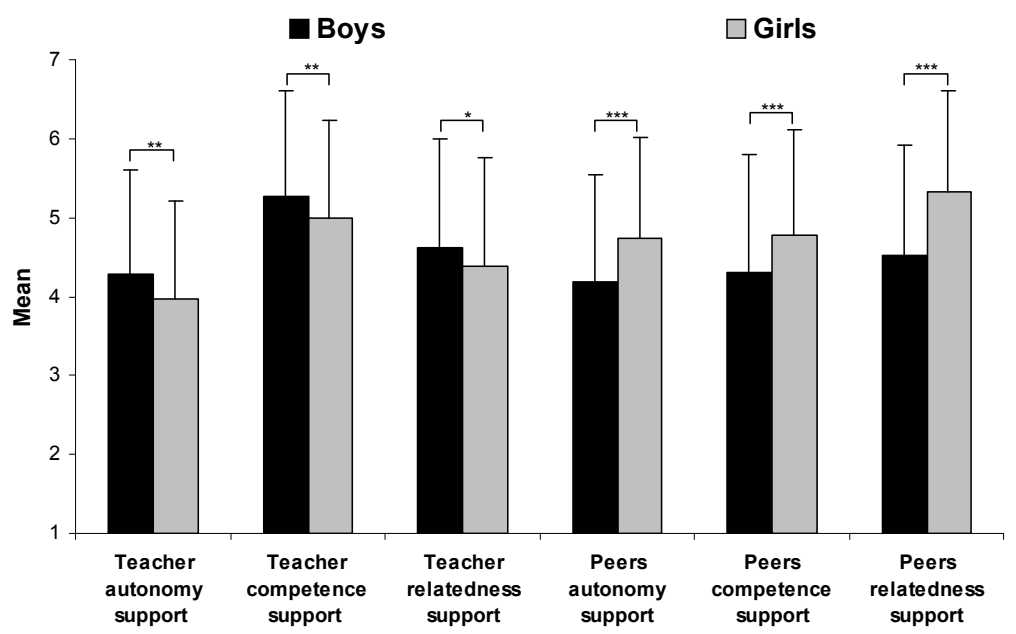

Figure 1. Gender differences for all study variables. ${ }^{*} \mathrm{p}<0.05,{ }^{*} \mathrm{p}<0.01$; $* * * \mathrm{p}<0.001$.

\section{DISCUSSION}

The aim of the present study was to investigate the effect of gender on perceptions of basic psychological needs support from both the teacher and peers in PE. Overall, the results showed that boys scored significantly higher than girls on perceptions of all three need support from the teacher, whereas girls scored significantly higher than boys on perceptions of all three need support from peers.

The results of this study showed that boys perceived significantly higher their PE teacher's autonomy-, competence-, and relatednesssupportive behaviour than girls. In general, this is consistent with previous studies indicated that PE teachers interact more often with boys than girls $[2,3,6,9]$. Specifically, results of the present study suggest that PE teachers provide boys with more choices and options in PE (i.e., one of the autonomy-supportive behaviours). Also, results 
suggest that PE teachers respect boys and interact more with them in a friendly way (i.e., relatedness-supportive behaviour). Finally, results revealed that $\mathrm{PE}$ teachers provide boys more often with positive statements allowing them to know that they are good at PE (i.e., competence-supportive behaviour). As regards to practical implications for practicing PE teachers, in order to enhance the perceptions of teacher's autonomy, competence, and relatedness needs support among girls, teachers should interact with them more frequently and involve them more often into the decision making process; let them know more often that they are doing well; and show more respect towards them. In doing so PE teachers are able better to satisfy girls' basic psychological needs in PE, which, in turn, would enhance selfdetermined learning [5].

The unique contribution of the present study to the extant PE literature is the finding revealed that girls perceived significantly higher their peers' autonomy-, competence-, and relatednesssupportive behaviour compared to boys. Specifically, girls perceived their peers (i) to be more friendly and respectful towards them during PE classes (i.e., relatedness-supportive behaviour); (ii) letting them more often to know that they are good at PE; and (iii) allowing them more often to decide about the strategies of games. These results suggest that girls tend to hold together and support each other in PE stronger than boys. In general, such gender difference is compatible with the social psychology theories documenting that females are more influenceable, especially by their peers. In line with social psychology theories, Baumeister and Kristin [1], for example, have also demonstrated that females are oriented more toward dyadic close relationships, whereas males are oriented toward a larger group. As regards to practical implications for practicing PE teachers, in order to enhance the perceptions of psychological needs support from peers among boys, teachers should create opportunities where students are able to interact more often and more closely with each other. According to the results of the study by Morgan and Carpenter [8], PE teachers should set up cooperative tasks in small groups more often. While doing so, PE teachers should guide students so that they will interact with each other in a basic psychological need-supportive way, which, in turn, should result in a students' learning that is more selfdetermined [5].

Although the present study provided some interesting and unique information about the effect of gender on basic psychological needs 
support from both the teacher and peers in PE among secondary school students in Estonia, the caution about the generalizability of the present findings should be taken. That is, the present sample does not represent the entire population of the secondary school students.

In summary, teacher should consider that boys and girls may vary in their perceptions of psychological needs supportive behaviours form the teacher and peers in PE. This knowledge should help practicing PE teachers to interact with their students more efficiently in order to facilitate the satisfaction of the basic psychological needs in PE, which, in turn, should result in self-determined learning.

\section{REFERENCES}

1. Baumeister R., Kristin L. S. (1997) What do men want? Gender differences and two spheres of belongingness: Comment on Cross and Madson. Psychol. Bull. 122: 38-44

2. Brown S., Brown D., Hussey K. (1996) Promote equality in the classroom. Strateg. J. Phys. Sport Educ. 9 (6): 19-22

3. Davis K. L. (2003) Teaching for gender equity in physical education: A review of literature. Woman Sport Phys. Activ. J. 12: 55-82

4. Deci E. L., Ryan, R. M. (1985) Intrinsic motivation and selfdetermination in human behavior. Plenum Press, New York

5. Deci E. L., Ryan R. M. (2000) The "What" and "Why" of goal pursuits: Human needs and the self-determination of behavior. Psychol. Inq. 11: 227-268

6. Dunbar R., O'Sullivan M. (1986) Effects of intervention on differential treatment of boys and girls in elementary physical education lessons. J. Teach. Phys. Educ. 5: 166-175

7. Martinek T. J. (1988) Confirmation of a teacher expectancy model: Student perceptions and causal attributions of teaching behaviours. Res. Q. Exerc. Sport. 59: 118-126

8. Morgan K., Carpenter P. J. (2002) Effects of manipulating the motivational climate in physical education lessons. Eur. Phys. Educ. Rev. 8 (3): 207-229

9. Nicaise V., Cogerino G., Fairclough S., Bois J., Davis K. (2007) Teacher feedback and interactions in physical education: Effects of student gender and physical activities. Eur. Phys. Educ. Rev. 13 (3): 319-337 
10. Ntoumanis N. (2005) A Prospective study of participation in optional school physical education using a self-determination theory framework. J. Educ. Psychol. 97: 444-453

11. Sage N. A., Kindermann T. A. (1999) Peer networks, behavior contingencies, and children's engagement in the classroom. MerrillPalmer Q. 454(1): 143-171

12. Standage M., Duda J. L., Ntoumanis N. (2005) A test of selfdetermination theory in school physical education. Br. J. Educ. Psychol. 75: 411-433

\section{ACKNOWLEDGEMENT}

This study was financially supported by the grant from the Estonian Ministry of Education and Research (SF0180036s07).

\section{Correspondence to:}

Roomet Viira

5 Jakobi Street, EE 51014 Tartu, Estonia

email: roomet.viira@ut.ee

tel: +372 7375289 